\title{
Progesterone inserts may help to improve breeding readiness in beef heifers
}

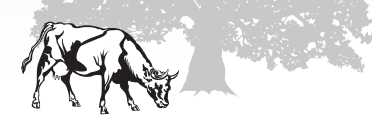

\author{
by Pedro H. Favetto, Bruce R. Hoar, Dan M. \\ Myers and Justin Tindall
}

The accurate determination of pubertal status in yearling beef heifers, possibly combined with the use of exogenous progesterone, allows females to produce the maximum number of calves over their lifetimes. This study aimed to determine the reliability of a reproductive tract scoring (RTS) system that combines manual palpation with ultrasound as a measure of pubertal status, and whether the treatment of heifers with progesterone-containing vaginal inserts - followed by breeding on the second estrus after removal of the insert - could result in increased conception rates compared to untreated heifers. Over 2 years, we found that RTS predicted pubertal status reasonably accurately. Progesterone-treated heifers were more likely to exhibit estrus than control heifers, but their overall breeding efficiency was not affected by progesterone treatment. Inadequate nutrition associated with increased pasture stocking density during both breeding seasons likely had a negative effect on the results of our study.

The primary economic goal of cow-
calf operators is to produce as
many calves per year as possible from
sexually mature females. Yearling
heifers should be enrolled in a breed-
ing program to calve as 2-year-olds,
maximizing the number of calves pro-
duced in their lifetimes (Wood-Follis
et al. 2004; Byerley, Staigmiller, et al.
1987). Consequently, they must be suf-
ficiently mature to be bred at 14 to 15
months of age. The ability to accurately
determine sexual maturity as a predic-

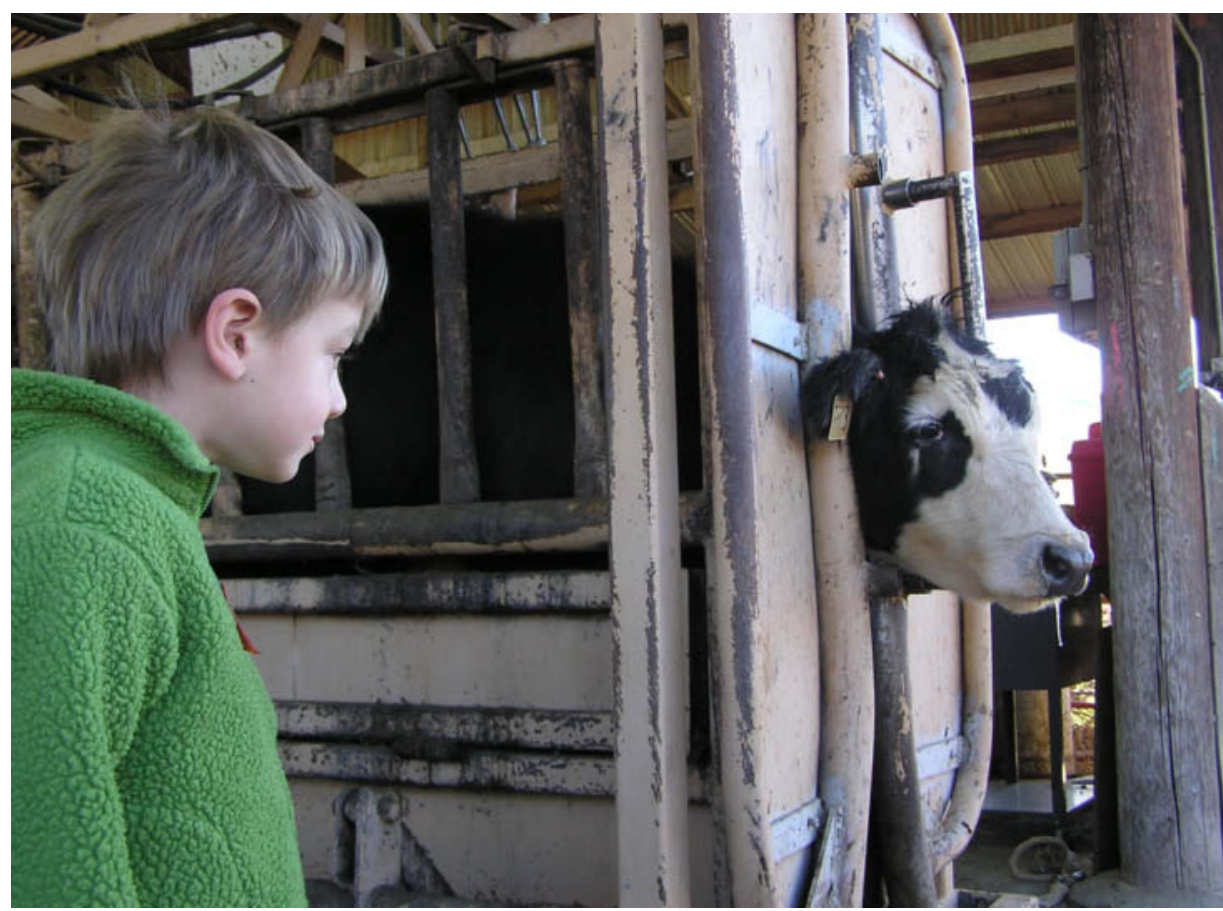

Researchers investigated methods to identify the pubertal status of beef heifers, in order to maximize calf production. Graeme Ernest-Hoar watches a cow being "worked" at the UC Sierra Foothill Extension Center.

tor of future reproductive efficiency is important so that producers can retain the heifers most likely to become pregnant at a young age in the herd.

Reproductive tract scoring (RTS) is performed by transrectal palpation that may be combined with ultrasonography of the uterine horns and ovarian structures (Rosenkrans and Hardin 2003). Heifers are categorized into five different groups based on uterine size and tone, and ovarian findings (Rosenkrans and Hardin 2003; Dahlen et al. 2003). The method considered most accurate measures progesterone levels in two separate blood samples taken 10 days apart, in order to determine whether the heifer is prepubertal or pubertal.

As females reach puberty, serum concentrations of sex hormones are modified due to normal fluctuations in the estrous cycle. After the first ovulation (pubertal estrus), progesterone levels are higher than any values previously observed (Gonzalez-Padilla, Wiltbank, et al. 1975). After the onset of pubertal estrus, progesterone follows a cyclic pattern; it is lowest on days 0 to 2 , increases to a maximum between days 12 and 15, and decreases rapidly 3 to 4 days before the next estrus (Donaldson et al. 1970).

The use of progesterone to influence the onset of puberty has been widely studied (Smidt and Majerciak 1971; Gonzalez-Padilla, Niswender, et al. 1975; Wood-Follis et al. 2004; Jaeger et al. 1992; Lucy et al. 2001; Colazo et al. 2003). Progesterone-based protocols have been tested for their effectiveness in inducing puberty and synchronizing estrus. The oral administration of a progestin, melengestrol acetate (MGA), for 14 days followed by an injection of 25 milligrams (mg) of prostaglandin $\mathrm{F}_{2 \alpha}\left(\mathrm{PGF}_{2 \alpha}\right) 17$ to 19 days after MGA withdrawal (Wood-Follis et al. 2004; Jaeger et al. 1992) was effective in inducing puberty. This confirmed that exogenous progesterone can successfully induce cyclicity in prepubertal heifers, and that the onset of puberty induced by progestin can be followed 
Nutrition is clearly an important

factor for the success of any reproductive management tool.

by the ability to maintain continued cyclic activity (Jaeger et al. 1992).

Another progesterone-based product, an intravaginal insert known as a controlled internal drug-releasing (CIDR) device, contains 1.38 grams of progesterone in elastic rubber molded over a nylon spine in a " $Y$ " shape. Unlike the standard protocol using MGA, CIDR inserts are in place for 7 to 10 days, reducing the treatment time and avoiding delays in the onset of the breeding season.

CIDRs can reduce the time to puberty in beef heifers and effectively synchronize estrus in cattle (Lucy et al. 2001; Colazo et al. 2003; Chenault et al. 2003). In these studies, after the CIDR implant was removed on the 7th day of treatment, a fixed-time artificial insemination was performed at the resulting estrus (Lucy et al. 2001). Consequently, prepubertal heifers that responded favorably to the treatment were artificially inseminated at the pubertal estrus. Unfortunately, this may result in lower pregnancy rates, because there is evidence of suboptimal fertility at pubertal estrus in beef heifers and other female mammals (Byerley, Staigmiller, et al. 1987). Previous studies have found that pregnancy rates were higher in heifers bred on the third estrus compared to those bred on the pubertal estrus (Byerley, Staigmiller, et al. 1987). This difference in pregnancy rates may be explained by a change in the progesterone-to-estrogen ratio between the first and third estrous cycles, resolving the early unfavorable uterine environment caused by higher progesterone and lower estrogen concentrations in the pubertal estrus (Byerley, Berardinelli, et al. 1987).

Given that the first estrus following the prepubertal stage may lead to the ovulation of subfertile ova, we conducted a further evaluation of CIDR inserts in order to collect important data on breeding efficiency (breeding age, interval to conception and pregnancy rate) in heifers treated with CIDR and bred on the second estrus following the onset of puberty. The goals of this

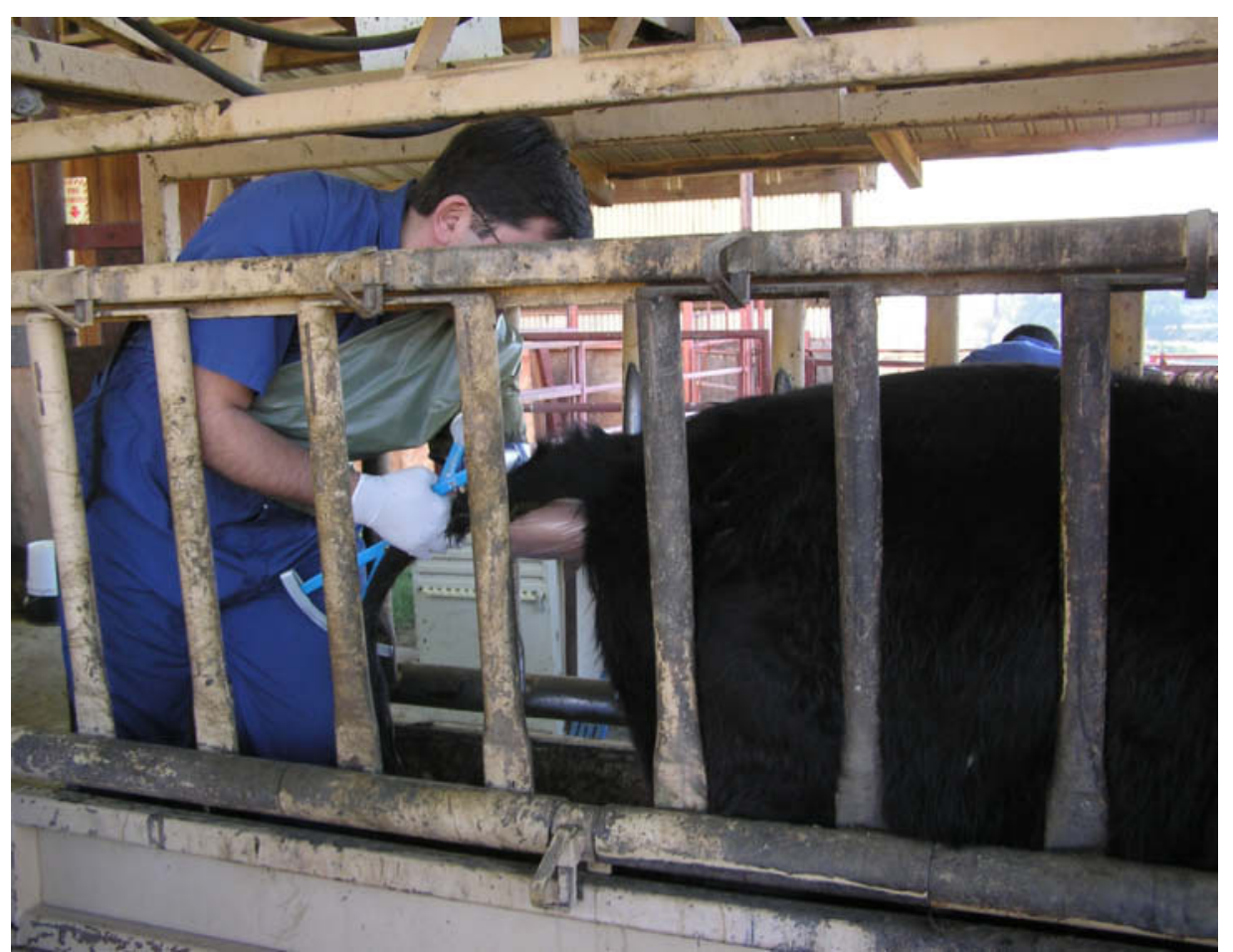

Progesterone inserts were administered by veterinarian Pedro Favetto to test whether puberty could be induced earlier in heifers.

study were to determine (1) the accuracy of RTS as a measure of pubertal status and (2) whether the treatment of heifers with CIDR inserts, followed by breeding on the second estrus following removal of the insert, could result in increased conception rates compared to untreated heifers under the same management conditions.

\section{Study animals}

Our 2-year study was performed using animals belonging to the UC Sierra Foothill Research and Extension Center (SFREC). We studied 201 (84 in year 1 and 117 in year 2) Black Angus and Hereford crossbred yearling heifers that were to be bred as part of routine management at SFREC. The UC Animal Care and Use Committee approved all protocols and procedures.

Heifers were initially transrectally palpated and examined with ultrasound by a single researcher to evaluate their reproductive status (pregnancy status and RTS) (Rosenkrans and Hardin 2003; Dahlen et al. 2003). Ultrasonography was used to measure ovarian structures and uterine horn diameter to more accurately determine the RTS (table 1) (Dahlen et al. 2003). A blood sample was collected to measure serum progesterone concentration, and a second blood sample was collected 10 days later. Additional data included body condition score, body weight, age and nutritional history of the group.

\begin{tabular}{|c|c|c|}
\hline \multicolumn{3}{|c|}{$\begin{array}{l}\text { TABLE 1. Reproductive tract score (RTS), based } \\
\text { on rectal palpation combined with ultrasound, } \\
\text { assigned to heifers according to uterine horn size } \\
\text { and ovarian structures on a scale of } 1 \text { to } 5\end{array}$} \\
\hline RTS & $\begin{array}{l}\text { Uterine horn } \\
\text { diameter }\end{array}$ & Ovarian structures \\
\hline \multicolumn{3}{|c|}{$\mathrm{mm}$} \\
\hline 1 & $<5$ & No palpable follicles \\
\hline 2 & $5-10$ & $8 \mathrm{~mm}$ follicles \\
\hline 3 & $10-15$ & $8-10 \mathrm{~mm}$ follicles \\
\hline 4 & $15-20$ & $>10 \mathrm{~mm}$ follicles \\
\hline 5 & $>20$ & $\begin{array}{l}>10 \mathrm{~mm} \text { follicles, } \\
\text { corpus luteum present }\end{array}$ \\
\hline
\end{tabular}



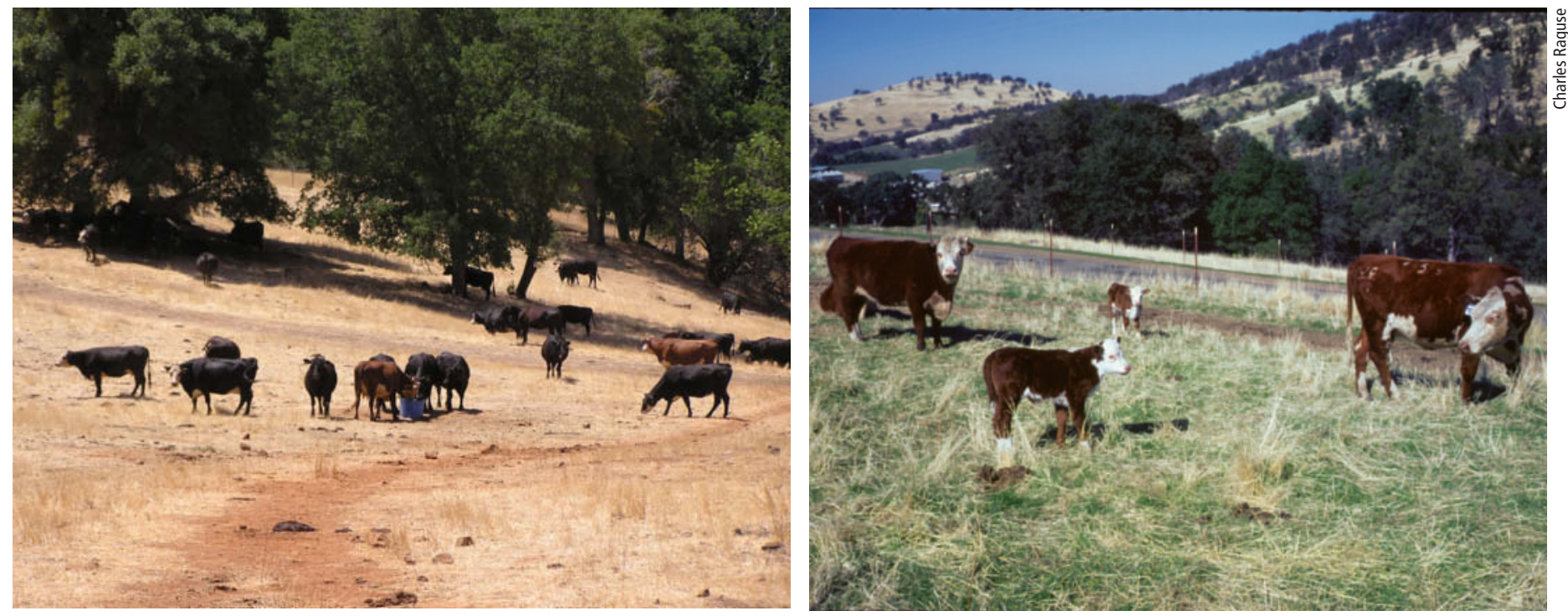

Reproductive tract scoring (RTS) and progesterone inserts may improve the breeding efficiency of heifers, but nutrition is an important limiting factor.

The RTS values, based on palpation and ultrasound measurements, were analyzed and used to assign the heifers to either prepubertal or pubertal groups. Heifers were blocked by pubertal status (RTS $\leq 3$, prepubertal; RTS $\geq$ 4 , pubertal), then randomly allocated into either a CIDR-treated or control group using a random-number generator.

To determine progesterone concentrations in the blood, we used a rapid, solid-phase microtitre plate enzyme immunoassay (EIA) (Munro and Stabenfeldt 1984). Briefly, the EIA uses progesterone 3-O-carboxymethyloxime-horseradish peroxidase as the labeled analyte, and antiserum (raised in rabbits) to a progesterone 11a-hemisuccinyl-bovine serum albumin (BSA) immunogen. The EIA was able to detect a lower threshold of 0.07 nanogram per milliliter (ng/ $\mathrm{ml}$ ) of progesterone. If either of the blood samples showed a progesterone concentration greater than $1 \mathrm{ng} / \mathrm{ml}$, the animal was considered pubertal. If both samples were below $1 \mathrm{ng} / \mathrm{ml}$, then the animal was considered prepubertal (Dow et al. 1982; Gonzalez-Padilla, Wiltbank, et al. 1975; Donaldson et al. 1970; Rosenkrans and Hardin 2003; Wehrman et al. 1996). The progesterone information was not used to assign the animals to treatment groups, but rather to analyze pubertal status and other data obtained throughout the study.

\section{CIDR implants}

CIDR implants were placed in the treatment group when the second blood sample was taken. This was considered day 0 (zero) of the clinical trial. Eight days later, the treatment group received an intramuscular dose of $25 \mathrm{mg}$ PGF $2_{\alpha}$.

The CIDR implants were removed the next day (day 9), and both groups were observed for estrus behavior for 1 hour, twice daily, for 7 days. In year 1, a simple synchronization protocol was started on day 17 in both the CIDR and control groups. It consisted of two injections of PGF $2_{\alpha}(25 \mathrm{mg}) 12$ days apart, followed by a single injection of gonadotrophin-releasing hormone (GnRH) (12 micrograms [ $\mu \mathrm{g}]) 48$ hours after the last PGF $2_{\alpha}$. In year 2 , the protocol was modified in an attempt to shorten the breeding season. A single dose of PGF $2_{\alpha}$ was injected on day 17 , followed by a single injection of GnRH 48 hours later. In both years, all heifers were artificially inseminated 20 hours after the GnRH injection by two experienced inseminators using frozen semen from a single bull. Three weeks after artificial insemination, the heifers were gathered in a single group and bulls were turned in for 2 months. All bulls had previously passed a breeding soundness examination. The bull-to-heifer ratio was approximately 1-to-20. At 30 days and 140 days after artificial insemination, all study animals were examined using ultrasound to detect pregnancy.

\section{Statistical analysis}

The sensitivity, specificity and overall "correct classification of palpation combined with ultrasound" was compared to "serum progesterone assay." In this trial, sensitivity was defined as the proportion of heifers classified as pubertal by RTS - given that they were truly pubertal as determined by progesterone assay - while specificity was defined as the proportion of heifers classified as prepubertal by RTS given that they were truly prepubertal. Overall correct classification was calculated as the sum of those correctly called pubertal and those correctly called prepubertal divided by the total number of heifers.

The final total proportion pregnant in each group in each year was compared using a Pearson's chi-square test. The ages and weights measured throughout the study were compared between the CIDR and control groups as well as between prepubertal and postpubertal heifers, using a one-way analysis of variance with a Bonferonni correction for multiple comparisons. A Kaplan-Meier survival analysis was performed, comparing time to pregnancy for both groups (CIDR and control). All the statistical analyses performed on the data were evaluated at a $5 \%$ significance level using a commercially available software program (SPSS Statistics 17.0, Chicago, Ill.). Results were calculated separately by 
year of study, and were also compared between years.

\section{Heifer classification, pregnancy}

There were no significant differences between the CIDR and control animals within a given year in age at artificial insemination, initial weight and weight at insemination, but animals in year 2 were younger at artificial insemination than in year 1 (the project was initiated earlier in year 2), and weighed significantly less than the control heifers in year 1 (and numerically, but not significantly, less than CIDR heifers) (table 2).

In year 1, 38\% of the heifers were prepubertal and $62 \%$ pubertal (table 3), based on serum progesterone levels at the beginning of the study, while in year 2 these values were $79.5 \%$ prepubertal and $20.5 \%$ pubertal. There were significantly more prepubertal heifers in year 2 than in year $1(P<$ 0.001 ), primarily associated with their younger age. The sensitivity of RTS for determining pubertal status increased from $76.9 \%$ to $83.3 \%$ from year 1 to year 2, while specificity increased from $40.6 \%$ to $68.8 \%$. The overall proportion of heifers correctly classified increased from $63.1 \%$ in year 1 to $71.8 \%$ in year 2 .

During the 7 days following removal of the CIDR inserts, estrous behavior was observed in $21 \%(9 / 42)$ and $24 \%(14 / 58)$ of the CIDR-treated heifers, and 7\% (3/42) and 15\% (9/59) of the control heifers in year 1 and year 2 , respectively. The observed differences were not statistically significant $(P=$ 0.12 and $P=0.26$, respectively).

Overall conception at first breeding was $23.8 \%$ and $17.9 \%$ (20/84 and 21/117) for year 1 and year 2, respectively (table 4). The combination of those pregnant from artificial insemination and natural service, after both groups were exposed to the bulls, was $75.0 \%$ and $70.1 \%$ (63/84 and 82/117) for the two study years. Pregnancy rates did not differ between CIDR and control groups in either year, either at first breeding $(P=0.61$ and $P=0.44$, respectively) or at the end of breeding season $(P=0.21$ and $P=0.89$, respectively).

\begin{tabular}{|c|c|c|c|c|}
\hline & \multicolumn{2}{|c|}{ Year 1} & \multicolumn{2}{|c|}{ Year 2} \\
\hline & $\begin{array}{l}\text { CIDR } \\
(n=42)\end{array}$ & $\begin{array}{l}\text { Control } \\
(n=42)\end{array}$ & $\begin{array}{l}\text { CIDR } \\
(n=58)\end{array}$ & $\begin{array}{l}\text { Control } \\
(n=59)\end{array}$ \\
\hline Age at $\mathrm{Al}$ (months) & $\begin{array}{c}13.8 a^{*} \\
(13.6 ; 14.0) \dagger\end{array}$ & $\begin{array}{c}14.0 \mathrm{a} \\
(13.7 ; 14.3)\end{array}$ & $\begin{array}{c}13.2 \mathrm{~b} \\
(13.1 ; 13.4)\end{array}$ & $\begin{array}{c}13.2 \mathrm{~b} \\
(13.0 ; 13.3)\end{array}$ \\
\hline Initial weight $(\mathrm{kg}) \ddagger$ & $\begin{array}{c}279.1 \mathrm{ab} \\
(271.8 ; 286.4)\end{array}$ & $\begin{array}{c}282.8 \mathrm{a} \\
(275.8 ; 289.8)\end{array}$ & $\begin{array}{c}268.7 \mathrm{~b} \\
(262.0 ; 275.2)\end{array}$ & $\begin{array}{c}269.2 b \\
(262.4 ; 276.1)\end{array}$ \\
\hline Weight at $\mathrm{Al}(\mathrm{kg}) \S$ & $\begin{array}{c}274.5 \\
(267.8 ; 281.2)\end{array}$ & $\begin{array}{c}276.8 \\
(269.1 ; 284.5)\end{array}$ & $\begin{array}{c}284.5 \\
(276.5 ; 292.4)\end{array}$ & $\begin{array}{c}283.5 \\
(276.3 ; 290.7)\end{array}$ \\
\hline $\begin{array}{l}\text { Weight gain between } \\
\text { enrollment and } \mathrm{Al}(\mathrm{kg})\end{array}$ & $\begin{array}{c}-4.6 a \\
(-7.4 ;-1.9)\end{array}$ & $\begin{array}{c}-6.0 \mathrm{a} \\
(-8.7 ;-2.3)\end{array}$ & $\begin{array}{c}15.8 \mathrm{~b} \\
(12.2 ; 19.4)\end{array}$ & $\begin{array}{c}14.3 \mathrm{~b} \\
(10.6 ; 18.0)\end{array}$ \\
\hline
\end{tabular}

TABLE 3. Agreement between serum progesterone levels and palpation combined with ultrasound (reproductive tract score [RTS]) as methods of determining pubertal status of beef heifers

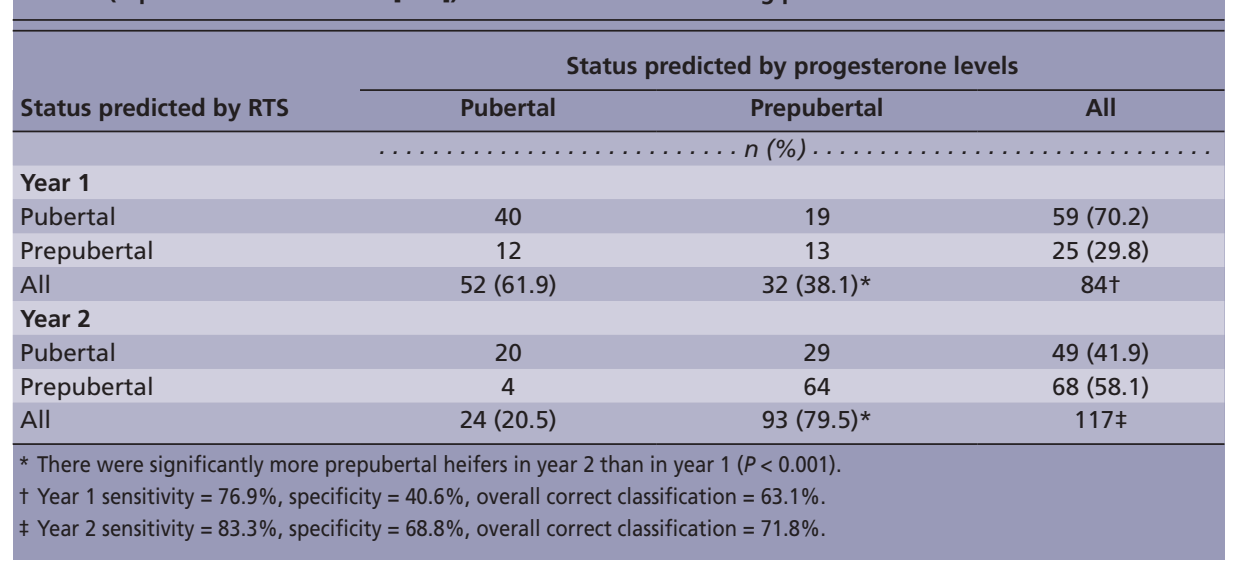

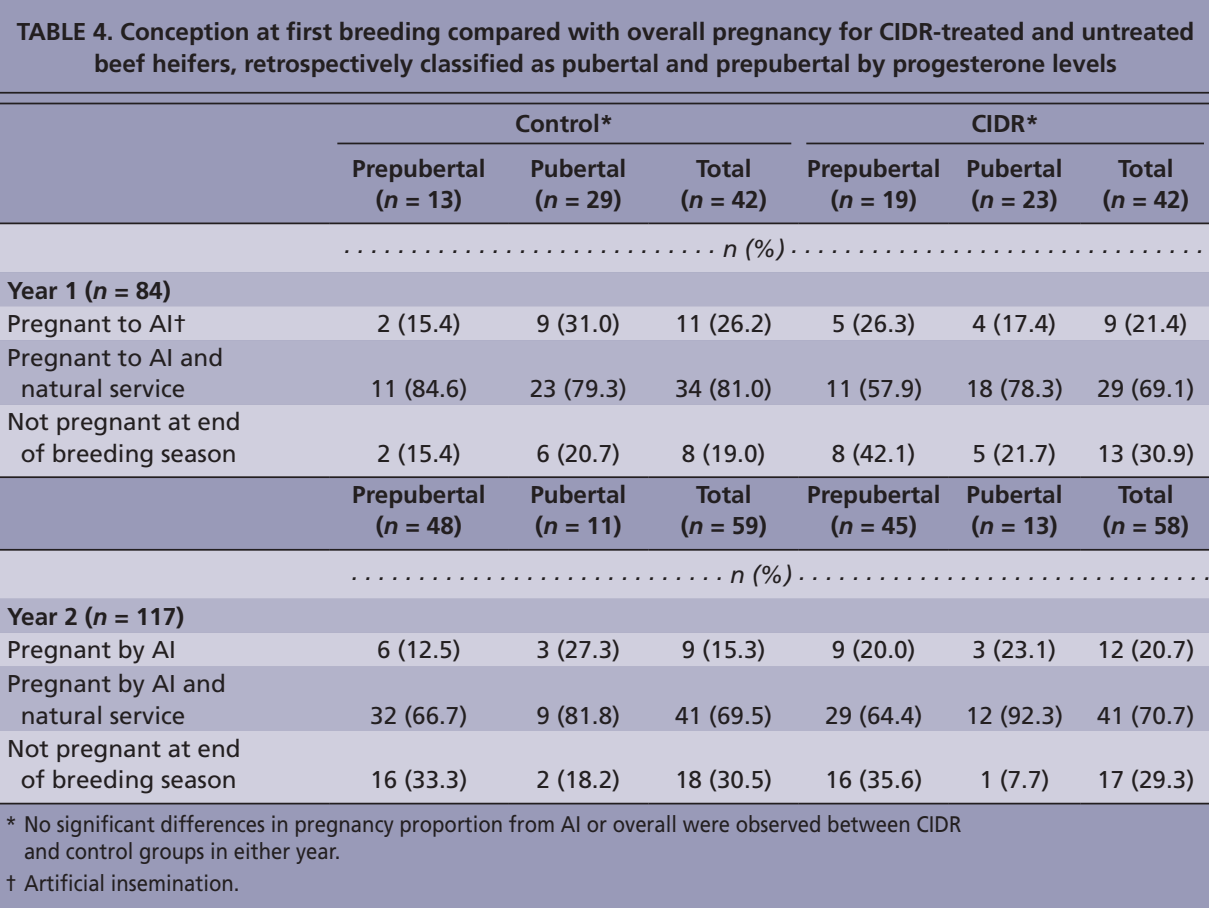




\begin{tabular}{|c|c|c|c|c|c|c|c|c|c|}
\hline \multicolumn{10}{|c|}{$\begin{array}{l}\text { TABLE 5. Mean age and weight comparison of heifers bred by } \\
\text { artificial insemination (Al), bull or not pregnant by Al or bull breeding }\end{array}$} \\
\hline & \multicolumn{3}{|c|}{ Al pregnancies } & \multicolumn{3}{|c|}{ Pregnancies w/bull } & \multicolumn{3}{|c|}{ Not pregnant } \\
\hline & Age & $\begin{array}{l}\text { Initial } \\
\text { weight }\end{array}$ & $\begin{array}{l}\text { Weight } \\
\text { at Al }\end{array}$ & Age & $\begin{array}{l}\text { Initial } \\
\text { weight }\end{array}$ & $\begin{array}{l}\text { Weight } \\
\text { at Al }\end{array}$ & Age & $\begin{array}{l}\text { Initial } \\
\text { weight }\end{array}$ & $\begin{array}{l}\text { Weight } \\
\text { at Al }\end{array}$ \\
\hline & months & $\ldots \ldots \ldots$ & $\ldots \ldots \ldots$ & months & $\ldots \ldots k$ & $\ldots \ldots$ & months & $\cdots \cdots k$ & $g \ldots \ldots$ \\
\hline \multicolumn{10}{|l|}{ Year 1} \\
\hline CIDR & 14.1 & 279.1 & 266.4 & 13.9 & 281.1 & 275.5 & 13.6 & 276.6 & 274.0 \\
\hline Control & 14.6 & 295.0 & 290.0 & 14.0 & 286.0 & 281.3 & 13.7 & 271.5 & 261.3 \\
\hline Total & 14.3 & 287.1 & 278.2 & 13.9 & 283.6 & 278.4 & 13.6 & 274.1 & 267.6 \\
\hline \multicolumn{10}{|l|}{ Year 2} \\
\hline CIDR & 13.4 & 276.7 & 289.3 & 13.2 & 272.1 & 282.0 & 13.2 & 256.4 & 267.5 \\
\hline Control & 13.1 & 277.6 & 286.8 & 13.2 & 276.2 & 290.8 & 13.1 & 252.6 & 268.9 \\
\hline Total & 13.3 & 277.1 & 288.2 & 13.2 & 274.3 & 286.6 & 13.1 & 254.4 & 268.2 \\
\hline
\end{tabular}

\begin{tabular}{|c|c|c|c|c|}
\hline \multicolumn{5}{|c|}{$\begin{array}{l}\text { TABLE 6. Age and weight comparison of heifers } \\
\text { classified as prepubertal and pubertal based on progesterone levels }\end{array}$} \\
\hline & \multicolumn{2}{|c|}{ Year 1} & \multicolumn{2}{|c|}{ Year 2} \\
\hline & $\begin{array}{l}\text { Prepubertal } \\
(n=32)\end{array}$ & $\begin{array}{l}\text { Pubertal } \\
(n=52)\end{array}$ & $\begin{array}{l}\text { Prepubertal } \\
(n=93)\end{array}$ & $\begin{array}{l}\text { Pubertal } \\
(n=24)\end{array}$ \\
\hline Age at $\mathrm{Al}$ (months) & $\begin{array}{c}13.4 \mathrm{a}^{*} \\
(13.2 ; 13.6) \dagger\end{array}$ & $\begin{array}{c}14.2 \mathrm{~b} \\
(13.9 ; 14.4)\end{array}$ & $\begin{array}{c}13.2 \mathrm{a} \\
(13.1 ; 13.3)\end{array}$ & $\begin{array}{c}13.3 a \\
(13.1 ; 13.5)\end{array}$ \\
\hline Initial weight (kg) & $\begin{array}{c}273.9 \mathrm{ab} \\
(267.2 ; 280.7)\end{array}$ & $\begin{array}{c}285.4 \mathrm{ab} \\
(278.6 ; 292.1)\end{array}$ & $\begin{array}{c}266.3 a \\
(260.9 ; 271.7)\end{array}$ & $\begin{array}{c}279.0 \mathrm{ab} \\
(270.4 ; 287.6)\end{array}$ \\
\hline Weight at $\mathrm{Al}(\mathrm{kg})$ & $\begin{array}{c}269.6 a \\
(262.9 ; 276.4)\end{array}$ & $\begin{array}{c}279.3 a \\
(272.4 ; 286.2)\end{array}$ & $\begin{array}{c}280.6 a \\
(274.6 ; 286.7)\end{array}$ & $\begin{array}{c}296.5 \mathrm{~b} \\
(286.7 ; 306.4)\end{array}$ \\
\hline $\begin{array}{l}\text { Weight gain between } \\
\text { enrollment and } \mathrm{Al}(\mathrm{kg})\end{array}$ & $\begin{array}{c}-4.3 a \\
(-7.3 ;-1.2)\end{array}$ & $\begin{array}{c}-6.1 a \\
(-7.9 ;-3.7)\end{array}$ & $\begin{array}{c}14.3 \mathrm{~b} \\
(12.2 ; 17.7)\end{array}$ & $\begin{array}{c}17.5 b \\
(10.8 ; 24.3)\end{array}$ \\
\hline
\end{tabular}

The average age at artificial insemination, average initial weight and average weight at artificial insemination were compared based on final pregnancy status, and the differences among nonpregnant heifers, heifers pregnant by the bull and heifers pregnant by artificial insemination were not significant (table 5). However, an upward trend was observed in age and weight when nonpregnant heifers were compared to heifers pregnant by the bull. A further increase was observed when heifers pregnant by the bull were compared to heifers pregnant by artificial insemination in the control group. This was consistent in both year 1 and year 2 , but less obvious in year 2 .

Heifers found to be prepubertal by progesterone levels in year 1 were younger at artificial insemination $(P<$ $0.001)$, weighed less initially $(P=0.025)$ and tended to weigh less at artificial insemination $(P=0.062)$ than pubertal heifers. In year 2 , prepubertal heifers tended to be younger $(P=0.16)$, weigh less initially $(P=0.029)$ and weigh less at artificial insemination $(P=0.014)$ than pubertal heifers (table 6). This is consistent with much of the work done by others on the association between weight, age and puberty.

Survival analysis showed no significant difference in the median days to pregnancy between treatments and between years of the study. The overall median number of days to pregnancy was 60 .

\section{Screening tests}

This study was designed to evaluate whether the treatment of prepubertal beef heifers with CIDR inserts could achieve the early expression of puberty and maintain cyclicity, thereby improving breeding efficiency by reducing the age at breeding and interval to conception, and increasing the pregnancy rate. However, while more heifers treated with CIDR inserts demonstrated estrous behavior, we found no effect on the proportion that became pregnant.

The proportion of heifers correctly classified as either pubertal or prepu- bertal improved between year 1 and year 2, likely due to the palpator's increased experience. We found that the ability to detect pubertal heifers accurately (sensitivity) was greater than the ability to detect prepubertal animals (specificity). These results are in general agreement with those of a previous study (Rosenkrans and Hardin 2003). Low specificity (high "false positive" rate) may be due to mistakenly identifying a developing corpus luteum (progesterone-secreting endocrine tissue that forms on the ovary immediately after ovulation) present and palpable between day 1 and day 4 of the estrous cycle but not secreting large quantities of progesterone for a mature corpus luteum. Low sensitivity (high "false negative" rate) may be due to luteal tissue being deeply embedded in ovarian stroma, making accurate identification difficult.

For these reasons, we conclude that RTS should not be used as the sole criterion for determining whether a heifer is to be retained within the breeding herd, but rather should be used as a screening test. This could be an important adjunct to current UC recommendations, which suggest using age and weight in selecting replacement heifers. With a sensitivity ranging from $76.9 \%$ to $83.3 \%$, $17 \%$ to $23 \%$ of heifers that are truly pubertal will be called prepubertal and be at risk of being culled. Conversely, with specificity ranging from $40.6 \%$ to $68.8 \%$, $31 \%$ to $59 \%$ of heifers that are prepubertal will be called pubertal.

\section{Nutritional deficiency suspected}

In this study, a greater number of CIDR-implanted heifers showed estrous behavior a week after treatment than nontreated heifers. This difference was statistically significant when data from the two years was combined, but not when examined separately. The estrous response to treatment was lower than expected (Wood-Follis et al. 2004; Lucy et al. 2001). There were no significant differences between the CIDR and 


\section{Reproductive tract scoring should not be used as the sole criterion for determining whether a heifer is to be retained within the breeding herd, but rather should be used as a screening test.}

control groups in overall pregnancy, pregnancy at first breeding or time to conception. Our findings were not in agreement with those presented by other researchers (Lucy et al. 2001), who found that the 3-day artificialinsemination pregnancy rates for beef heifers were $8 \%, 14 \%$ and $39 \%$ for controls, animals treated with $\mathrm{PGF}_{2 \alpha}$, and animals treated with CIDR plus $\mathrm{PGF}_{2 \alpha}$ respectively.

We believe that the discrepancy in our results is attributable to a nutrition deficiency combined with young age during the trial period. Given that the age of puberty onset is influenced by a heifer's nutritional status and genetic background (Schillo et al. 1992; Dow et al. 1982), these variables must be considered when analyzing the results of a heifer-breeding program. The average breeding age of the heifers in our study was lower than normally accepted in beef operations (Stull et al. 2007). Dow et al. (1982) observed that beef heifers of continental crosses attained puberty between 11.5 and 19.5 months. In year 1 , our study heifers were 13.9 months of age at breeding, and in year 2 they were significantly younger (13.2 months). The young age of animals in this study undoubtedly affected the onset of puberty.

A lack of appropriate weight gain was a major problem during the study period in both years. From first evaluation to first breeding, the study animals either lost considerable weight (year 1) or gained only slightly (year 2). Heifers should maintain continuous growth to facilitate breeding, reach a normal adult frame size and reduce the risk of problems at parturition. Dry conditions during both years (due to late rainfall that delayed germination and high summer temperatures) probably contributed to the poor weight gain. In addition, stocking density was increased during these two years. For this trial, a greater number of heifers than normal was retained for breeding, but due to specific management procedures they were pastured on the same field as in previ- ous years. While nutritional problems affected our study, the results provide further evidence that good nutrition is a key element in all areas of animal husbandry and is critical for every breeding protocol (Schillo et al. 1992; Donaldson et al. 1970; Patterson et al. 1992).

Based on the results of this trial, we conclude that RTS can provide important information related to the pubertal status of heifers, but should not be used as the sole criterion for selecting replacement females. Also, CIDR inserts only marginally improve the breeding efficiency of prepubertal beef heifers when nutrition is limiting. Nutrition is clearly an important fac-

\section{References}

Byerley DJ, Berardinelli JG, Staigmiller RB, et al. 1987. Progesterone concentrations in beef heifers bred at puberty or third estrus. J Anim Sci 65:1571-5.

Byerley DJ, Staigmiller RB, Berardinelli JG, et al. 1987 Pregnancy rates of beef heifers bred either on pubertal or third estrus. J Anim Sci 65:645-50.

Chenault JR, Boucher JF, Dame KJ, et al. 2003. Intravaginal progesterone insert to synchronize return to estrus of previously inseminated dairy cows. J Dairy Sci 86:2039-49

Colazo MG, Kastelic JP, Mapletoft RJ. 2003. Effects of estradiol cypionate (ECP) on ovarian follicular dynamics, synchrony of ovulation, and fertility in CIDR-based, fixed-time Al programs in beef heifers. Theriogenology 60:855-65.

Dahlen CR, Lamb GC, Zehnder CM, et al. 2003. Fixedtime insemination in peripubertal, lightweight replacement beef heifers after estrus synchronization with $\mathrm{PGF}_{2 \alpha}$ and $\mathrm{GnRH}$. Theriogenology 59:1827-37.

Donaldson LE, Bassett JM, Thorburn GD. 1970. Peripheral plasma progesterone concentration of cows during puberty, oestrous cycles, pregnancy and lactation, and the effects of under-nutrition or exogenous oxytocin on progesterone concentration. J Endocrinol 48:599-614.

Dow Jr JS, Moore JD, Bailey CM, et al. 1982. Onset of puberty in heifers of diverse beef breeds and crosses. J Anim Sci 55:1041-7

Gonzalez-Padilla E, Niswender GD, Wiltbank JN. 1975. Puberty in beef heifers. II. Effect of injections of progesterone and estradiol-17ß on serum LH, FSH and ovarian activity. J Anim Sci 40:1105-9.

Gonzalez-Padilla E, Wiltbank JN, Niswender GD. 1975. Puberty in beef heifers. I. The interrelationship between pituitary, hypothalamic and ovarian hormones. J Anim Sci 40:1091-104. tor for the success of any reproductive management tool. Adequate nutrition and optimal breeding efficiency enable producers to reduce the economic costs associated with increased feeding to maintain nonpregnant females, the loss of nonpregnant breeding animals due to culling, and the need to provide replacement breeding females.

P.H. Favetto is Veterinarian, Riverbank, CA; B.R. Hoar is Assistant Professor, School of Veterinary Medicine, UC Davis; and D.M. Myers is Operations Manager, and J. Tindall is Animal Health Technician, UC Sierra Foothill Research and Extension Center, Browns Valley, CA.

Jaeger JR, Whittier JC, Corah LR, et al. 1992. Reproductive response of yearling beef heifers to a melengestrol acetate-prostaglandin ${ }_{2 \alpha}$ estrus synchronization system. J Anim Sci 70:2622-7.

Lucy MC, Billings HJ, Butler WR, et al. 2001. Efficacy of an intravaginal progesterone insert and an injection of $\mathrm{PGF}_{2 \alpha}$ for synchronizing estrus and shortening the interval to pregnancy in postpartum beef cows, peripubertal beef heifers, and dairy heifers. J Anim Sci 79:982-95

Munro C, Stabenfeldt G. 1984. Development of a microtitre plate enzyme immunoassay for the determination of progesterone. J Endocrinol 101:41-9.

Patterson DJ, Perry RC, Kiracofe GH, et al. 1992. Management considerations in heifer development and puberty. J Anim Sci 70:4018-35.

Rosenkrans KS, Hardin DK. 2003. Repeatability and accuracy of reproductive tract scoring to determine pubertal status in beef heifers. Theriogenology 59:1087-92.

Schillo KK, Hall JB, Hileman SM. 1992. Effects of nutrition and season on the onset of puberty in the beef heifer. J Anim Sci 70:3994-4005

Smidt D, Majerciak P. 1971. [Results of experiments to influence the onset of puberty in animals (author's transl.)]. J Neurovisc Relat Suppl 10:98-106.

Stull C, Barry S, Jensen W. 2007. Beef Care Practices. UC ANR Publication 8257. http://ucanr.org/freepubs/ docs/8257.pdf (accessed Nov. 24, 2009).

Wehrman ME, Kojima FN, Sanchez T, et al. 1996. Incidence of precocious puberty in developing beef heifers. J Anim Sci 74:2462-7.

Wood-Follis SL, Kojima FN, Lucy MC, et al. 2004 Estrus synchronization in beef heifers with progestin based protocols. I. Differences in response based on pubertal status at the initiation of treatment. Theriogenology 62:1518-28. 